\title{
THE 'BASEBALL' ORBITAL IMPLANT: A PROSPECTIVE STUDY
}

\author{
B. LEATHERBARROW, J. KWARTZ, S. SUNDERLAND, R. BRAMMAR and E. NICHOL \\ Manchester
}

\begin{abstract}
SUMMARY
The 'baseball' orbital implant was described by Frueh and Felker in 1976. Although this implant was originally described for use as a secondary implant, it has also been widely used as a primary implant at the time of enucleation. This prospective study evaluated the effectiveness of this implant used both primarily and secondarily. Fortyfour patients were implanted between April 1990 and May 1991, 19 of the implants being primary and 25 secondary. A standardised operative and post-operative protocol was followed. The mean follow-up time was 31 months (range 24-36 months). The patients were evaluated for the degree of volume replacement, implant and associated prosthesis motility, secondary eyelid and socket problems, patient satisfaction, the need for further surgery and post-operative complications. The overall results achieved by primary implantation were superior to those of secondary implantation. Our results suggest that this implant provides a satisfactory functional and cosmetic rehabilitation of the anophthalmic patient with few complications.
\end{abstract}

The goals which we should strive to achieve in the rehabilitation of the anophthalmic patient are to provide the patient with a comfortable prosthesis (artificial eye) which has as natural an appearance as possible and a degree of motility which mimics that of the fellow eye in all directions, with the minimum of socket complications. It is now recognised that these goals can only be achieved satisfactorily with the use of an intraorbital implant. ${ }^{1-3}$ In the absence of an intraorbital implant, the volume deficit from loss of the eye leads to what has been referred to as the 'post-enucleation socket syndrome' with a retraction or ptosis of the upper eyelid, a deep upper lid sulcus, a lax lower eyelid and an enophthalmic appearance ${ }^{4.5}$ (Fig. 1).

Since Mules first implanted a glass sphere in $1885{ }^{6}{ }^{6}$ there has been a plethora of different intraorbital implants described. ${ }^{7-12}$ The large number of designs attests to the fact that none has been ideal, and indeed many have fallen

Correspondence to: Mr B. Leatherbarrow, Manchester Royal Eye Hospital, Oxford Road, Manchester M13 9WH. UK.

Eye (1994) 8, 569-576

(C) 1994 Royal College of Ophthalmologists into disrepute because of their unacceptable complication rate. The implants have varied in size, shape and material. They have been buried or partially exposed, and integrated or non-integrated. Recently there has been a resurgence of interest in the direct integration of implant and prosthesis with the development of the porous hydroxyapatite spherical implant. ${ }^{13.14}$ The long-term benefits and risks

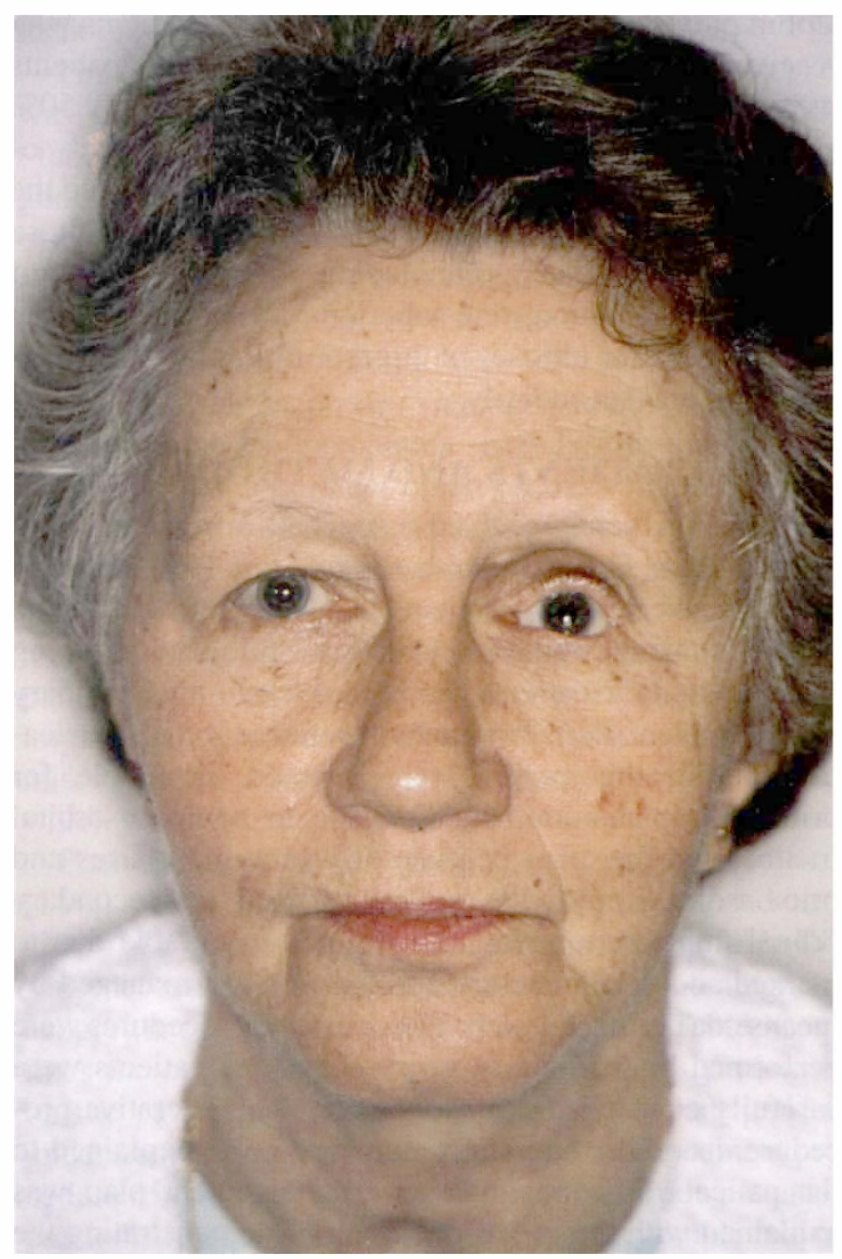

Fig. 1. A patient demonstrating the typical features of a postenucleation socket syndrome. 


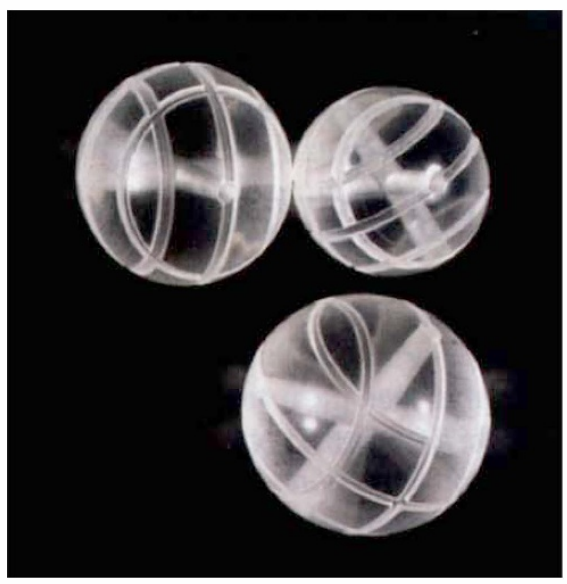

(a)

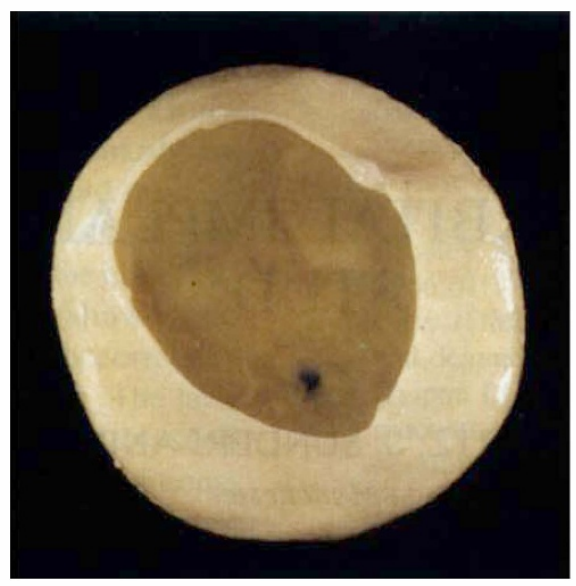

(b)

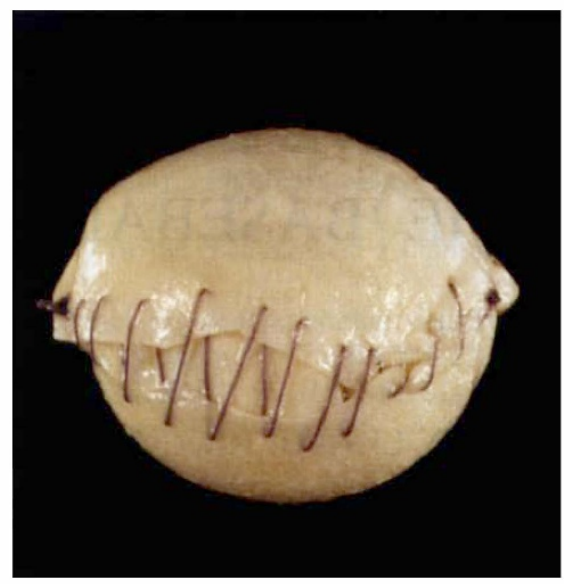

(c)

Fig. 2. (a) Acrylic ball implants. (b) A donor scleral shell. (c) A typical 'baseball' implant.

associated with this implant, together with its complications, remain to be seen.

The 'baseball' implant, an acrylic ball wrapped in an envelope of donor sclera, was described in 1976 by Frueh and Felker ${ }^{15}$ (Fig. 2). This implant was originally described for use as a secondary implant, but it has also been widely used as a primary implant. In 1985 Tyers and Collin published a retrospective study of 39 patients who received this type of implant.' Only 6 of these patients were implanted primarily and of these implants only $50 \%$ were retained. Subsequently, in a retrospective study of 114 patients published in 1990, Smit et al. ${ }^{16}$ compared the results of baseball implants inserted primarily with those implanted secondarily, concluding that the results of primary implantation were superior. ${ }^{16}$ We set out to study prospectively the efficacy of this type of implant used both primarily and secondarily.

\section{PATIENTS AND METHODS}

Forty-four patients received a baseball implant at Manchester Royal Eye Hospital between April 1990 and May 1991. Nineteen of the patients had been referred for an enucleation and orbital implantation while the remaining 25 anophthalmic patients had been referred for secondary orbital implantation. Two patients referred for an enucleation during this period were deemed unsuitable for primary implantation, the first due to complex orbital trauma, and the other because of orbital metastases and prior radiotherapy. One patient referred for secondary orbital implantation was also deemed unsuitable due to marked socket contracture and was instead managed by means of a dermis fat graft. The operative procedures were performed by a single surgeon (B.L.). All patients were carefully counselled prior to surgery. The operative procedure, its goals, limitations and risks were explained to the patients. The post-operative management plan was explained with the use of photographs demonstrating the appearance expected in the early post-operative course, and with a demonstration of sample socket conformers and prostheses. A patient information booklet was also used. The counselling was undertaken by a team con- sisting of the surgeon, two ocularists and a nurse (herself anophthalmic).

A standard protocol was followed in all cases. Pre- and post-operative photographs of the patients were taken. The patients were given a suppository of $100 \mathrm{mg}$ indomethacin 6 hours pre-operatively followed by $25 \mathrm{mg}$ orally t.i.d. for 2 weeks post-operatively, unless this was contraindicated or not tolerated. The surgery was performed under general anaesthesia. An intravenous injection of cefuroxime $750 \mathrm{mg}$ was given intraoperatively (erythromycin was substituted in patients with a history of penicillin allergy) followed by cephradine (or erythromycin) $500 \mathrm{mg}$ orally q.i.d. for 1 week post-operatively. A pressure dressing was applied at the completion of surgery and left in situ for 48 hours post-operatively. A socket conformer of suitable size and shape was then inserted by the ocularist unless precluded by excessive socket oedema, in which case a pressure dressing was reapplied and the patient fitted with the conformer after a further 48 hours. Topical antibiotic drops were used for 6 weeks postoperatively. The patients were examined at 48 hours, 2 weeks and 6 weeks post-operatively. They were then handed over to the ocularists and fitted with a custommade prosthesis after a standard impression had been taken. The patients were reviewed at intervals varying from 3 to 6 months. A final review examination was undertaken during the period April to June 1993. At this examination the patients were examined by the surgeon (B.L.), the ocularists, and by the orthoptist. The following parameters were assessed and recorded by the surgeon except where otherwise stated:

1. The degree of volume replacement provided by the combination of the implant and prosthesis as assessed by quantitative measurements performed using an exophthalmometer with the prosthesis in situ. and by qualitative assessments of any upper lid sulcus deformity. The sulcus deformity was graded into four categories: absent, mild, moderate or severe.

2. The location of the implant in the socket.

3. The motility of the baseball implant, which was subjectively graded as good, fair or poor. 
4. The motility of the prosthesis as recorded by the orthoptist, who was not aware of the primary or secondary status of the implant. Using a Lister perimeter to record the excursions of the prosthesis, the patients were asked to follow a fixation light horizontally. Vertical movements were not recorded. The point at which the corneal reflections deviated from a symmetrical position was recorded. The results were recorded as good, fair or poor. A good result was a total symmetrical horizontal movement of $20^{\circ}$ or more, a fair result was a total symmetrical horizontal movement of at least $10^{\circ}$, while lesser degrees of symmetrical movement were recorded as poor.

5. The presence of any lagophthalmos.

6 . The status of the socket and fornices.

7. The presence of lower eyelid laxity.

8. The requirement for further socket or eyelid surgery.

9. The nature of any post-operative complications.

10. The cosmetic result. Each patient was asked to grade the cosmetic result subjectively as good, fair or poor. The ocularist (S.S.) similarly graded the cosmetic result of each patient.

The patients' hospital records and histopathological reports were reviewed to determine the indications for the patients' enucleation.

\section{SURGICAL TECHNIQUE}

The implants consisted of an acrylic sphere covered with donor sclera (Mersilene mesh was substituted in 3 cases due to lack of availability of sclera). The surgical technique used for both primary and secondary implants was as described by Tyers and Collin.' The implants were inserted into the intraconal fat space posterior to the posterior layer of Tenon's fascia. In the secondary group no specific attempt was made to locate the extraocular muscles as this causes unnecessary trauma to the socket. Instead, the Tenon's fascia in the region where each rectus muscle had been seen to be active in the pre-operative socket examination was attached to the sclera. In the primary implant group, in addition to the four rectus muscles the inferior oblique muscle was also attached to the sclera in all cases to provide additional support for the implant. Attaching these muscles to the sclera partially closed the posterior layer of Tenon's fascia. Additional interrupted sutures were placed to effect a complete closure of this layer. Anterior Tenon's fascia and the conjunctiva were closed as separate layers. This technique provided a secure three-layer closure anterior to the implant. The size of implant required was carefully assessed by a trial implantation of a sphere prior to wrapping with sclera or Mersilene mesh, ensuring that the posterior Tenon's fascia could be closed over the implant without undue tension.

\section{RESULTS}

The age range of the patients was 9-83 years (mean 48 years). There were 24 males and 20 females. The mean follow-up time of the patients was 31 months (range 24-36 months). The indications for enucleation are shown in Table I ( 2 of the anophthalmic patients had previously undergone an evisceration).

The sizes of implants used are shown in Table II. The size of implant most frequently selected for both primary and secondary groups was $18 \mathrm{~mm}$.

The differences in Hertel exophthalmometry measurements between the fellow eye and the prosthesis are shown in Table III. The, range was from $0 \mathrm{~mm}$ to $3 \mathrm{~mm}$ with a mean of $1 \mathrm{~mm}$. Fifteen per cent of the primary implant cases were left with a degree of relative enophthalmos of $2 \mathrm{~mm}$ or greater versus $48 \%$ of the secondary implant cases.

The results of the qualitative assessment of the degree of residual upper eyelid sulcus deformity are shown in Table IV. The deformity was moderate or severe in only $5 \%$ of the primary implant group but present to this degree in $56 \%$ of the secondary implant group.

Three $(12 \%)$ of the secondary implants migrated to an eccentric location (Table V). One of these implants interfered with prosthetic fitting and had to be removed. All of the implants placed primarily remained in a central location.

The degree of motility of the implant within the socket was far superior overall in the primary implant group (Table VI). The motility of the implant was deemed to be good in $79 \%$ of the primary implant patients versus $20 \%$ of the secondary implant patients. Although the overall resultant motility of the prosthesis was better in the primary implant group, $10 \%$ of these patients were left with a poor motility result (Table VII).

Three of the secondary implant patients experienced post-operative lagophthalmos secondary to upper eyelid retraction with a mild entropion (Table VIII), but in each case this had been present pre-operatively. All of the primary implant group patients had normal eyelid closure. The status of each socket was healthy with no inflammatory signs but excess discharge was present in those patients with lagophthalmos. In one of the secondary implant group patients the inferior fornix was compromised due to inferotemporal migration of the implant which was subsequently removed.

Post-operative lower eyelid laxity was present in 3 $(16 \%)$ of the primary implant group patients and in 5 (20\%) of the secondary implant group patients (Table IX). This necessitated a secondary lower lid tightening procedure (lateral tarsal strip) in these patients. Table X outlines the other additional surgical procedures performed on the patients. Four of the secondary implant patients underwent an anterior approach levator advancement procedure for post-operative ptosis. In two of these patients a ptosis had been present prior to secondary implantation. An upper lid entropion had been present pre-operatively in the 3 patients who required upper lid entropion surgery. One implant was removed due to migration. Additional surgery to address a residual volume deficit was deemed to 
Table I. Indications for enucleation

\begin{tabular}{|c|c|c|}
\hline & $\begin{array}{c}\text { Primary implant } \\
\text { group }(n=19)\end{array}$ & $\begin{array}{l}\text { Secondary implant } \\
\text { group }(n=25)\end{array}$ \\
\hline Painful blind eye & $14(74 \%)$ & $7(28 \%)$ \\
\hline Rubeotic glaucoma & 4 & 2 \\
\hline Failed retinal reattachment surgery & 2 & 1 \\
\hline Buphthalmos & 1 & 0 \\
\hline Previous trauma & 4 & 3 \\
\hline Iatrogenic & 2 & 1 \\
\hline Uveitis & 1 & 0 \\
\hline Choroidal melanoma & $3(16 \%)$ & $6(24 \%)$ \\
\hline Penetrating injury & $2(10 \%)$ & $12(48 \%)$ \\
\hline
\end{tabular}

Values are $n(\%)$.

Table II. Implant size

\begin{tabular}{lcc}
\hline Size of ball $(\mathrm{mm})$ & $\begin{array}{c}\text { Primary implant } \\
\text { group }(n=19)\end{array}$ & $\begin{array}{c}\text { Secondary implant } \\
\text { group }(n=25)\end{array}$ \\
\hline 16 & $1(5 \%)$ & $1(4 \%)$ \\
18 & $14(74 \%)$ & $19(76 \%)$ \\
20 & $4(21 \%)$ & $5(20 \%)$ \\
\hline
\end{tabular}

Values are $n(\%)$.

Table IV. Qualitative assessment of upper eyelid sulcus deformity

\begin{tabular}{lcc}
\hline Sulcus deformity & $\begin{array}{c}\text { Primary implant } \\
\text { group }(n=19)\end{array}$ & $\begin{array}{c}\text { Secondary implant } \\
\text { group }(n=25)\end{array}$ \\
\hline Absent & $13(68 \%)$ & $3(12 \%)$ \\
Mild & $5(27 \%)$ & $8(32 \%)$ \\
Moderate & 0 & $13(52 \%)$ \\
Severe & $1(5 \%)$ & $1(4 \%)$ \\
\hline
\end{tabular}

Values are $n(\%)$.

Table VI. Surgeon's assessment of implant motility

\begin{tabular}{lcc}
\hline Result & $\begin{array}{c}\text { Primary implant } \\
\text { group }(n=19)\end{array}$ & $\begin{array}{c}\text { Secondary implant } \\
\text { group }(n=25)\end{array}$ \\
\hline Good & $15(79 \%)$ & $5(20 \%)$ \\
Fair & $4(21 \%)$ & $12(48 \%)$ \\
Poor & 0 & $8(32 \%)$ \\
\hline
\end{tabular}

Values are $n(\%)$.

Table VIII. Post-operative lagophthalmos

\begin{tabular}{lcc}
\hline Lagophthalmos & $\begin{array}{c}\text { Primary implant } \\
\text { group }(n=19)\end{array}$ & $\begin{array}{c}\text { Secondary implant } \\
\text { group }(n=25)\end{array}$ \\
\hline Absent & $19(100 \%)$ & $22(88 \%)$ \\
Present & 0 & $3(12 \%)$ \\
\hline
\end{tabular}

Values are $n(\%)$.

be required in $1(5 \%)$ of the primary implant group and in $14(56 \%)$ of the secondary implant group. This was undertaken in 3 patients of the secondary implant group in the form of a subperiosteal implant. One patient declined further socket surgery but instead underwent a contralateral 'camouflage' blepharoplasty to diminish the cosmetic effects of an upper lid sulcus deformity. The remaining patients with a residual volume deficit declined further surgery.

There were no operative complications. The post-operative complications are listed in Table XI. The only complication associated with the primary group was
Table III. Degree of relative enophthalmos of prosthesis

\begin{tabular}{lcc}
\hline Difference $(\mathrm{mm})$ & $\begin{array}{c}\text { Primary implant } \\
\text { group }(n=19)\end{array}$ & $\begin{array}{c}\text { Secondary implant } \\
\text { group }(n=25)\end{array}$ \\
\hline 0 & $9(48 \%)$ & $9(36 \%)$ \\
1 & $7(37 \%)$ & $4(16 \%)$ \\
2 & $2(10 \%)$ & $7(28 \%)$ \\
3 & $1(5 \%)$ & $5(20 \%)$ \\
\hline
\end{tabular}

Values are $n(\%)$.

Table V. Location of implant in socket

\begin{tabular}{lcc}
\hline Location & $\begin{array}{c}\text { Primary implant } \\
\text { group }(n=19)\end{array}$ & $\begin{array}{c}\text { Secondary implant } \\
\text { group }(n=25)\end{array}$ \\
\hline Central & $19(100 \%)$ & $22(88 \%)$ \\
Displaced & 0 & $3(12 \%)$ \\
\hline
\end{tabular}

Values are $n(\%)$.

Table VII. Orthoptist's assessment of prosthesis motility

\begin{tabular}{lcc}
\hline Result & $\begin{array}{c}\text { Primary implant } \\
\text { group }(n=19)\end{array}$ & $\begin{array}{c}\text { Secondary implant } \\
\text { group }(n=25)\end{array}$ \\
\hline Good & $8(42 \%)$ & $1(4 \%)$ \\
Fair & $9(48 \%)$ & $10(40 \%)$ \\
Poor & $2(10 \%)$ & $14(56 \%)$ \\
\hline
\end{tabular}

Values are $n(\%)$.

Table IX. Post-operative lower eyelid laxity

\begin{tabular}{lcc}
\hline Lower lid laxity & Primary implant & $\begin{array}{c}\text { Secondary implant } \\
\text { group }(n=25)\end{array}$ \\
\hline Absent & group $(n=19)$ & grou \\
Present & $16(84 \%)$ & $20(80 \%)$ \\
\hline Values a & $3(16 \%)$ & $5(20 \%)$ \\
\hline
\end{tabular}

Values are $n(\%)$.

conjunctival dehiscence in 2 cases requiring a simple conjunctival resuture in 1 case, and a small buccal mucous membrane graft in the other. The complication rate was higher in the secondary implant group. In 3 of the patients the implant migrated to an inferotemporal location in the socket causing difficulties with satisfactory fitting of the prosthesis. Two patients were left with a ptosis following implantation. Severe pain affected one patient. This subsided after 3 days. There were no serious complications.

Table XII outlines the subjective assessment of the overall cosmetic result by the ocularist, while Table XIII outlines the patients' own assessment of the overall 
Table X. Additional surgical procedures undertaken

\begin{tabular}{lcc}
\hline Surgical procedures & $\begin{array}{c}\text { Primary implant } \\
\text { group }(n=19)\end{array}$ & $\begin{array}{c}\text { Secondary implant } \\
\text { group }(n=25)\end{array}$ \\
\hline Ptosis surgery & 0 & $4(16 \%)$ \\
Subperiosteal implant & 0 & $3(12 \%)$ \\
Lower lid lateral tarsal strip & $2(10 \%)$ & $6(24 \%)$ \\
Removal of baseball implant & 0 & 1 \\
Mucous membrane graft & $1(5 \%)$ & 0 \\
Conjunctival resuture & $1(5 \%)$ & 0 \\
Upper lid entropion repair & 0 & $3(12 \%)$ \\
Contralateral 'camouflage' blepharoplasty & 0 & 1 \\
\hline
\end{tabular}

Values are $n(\%)$.

Table XI. Post-operative complications

\begin{tabular}{lcc}
\hline Complications & $\begin{array}{c}\text { Primary implant } \\
\text { group }(n=19)\end{array}$ & $\begin{array}{c}\text { Secondary implant } \\
\text { group }(n=25)\end{array}$ \\
\hline None & $17(90 \%)$ & $18(72 \%)$ \\
Migration of implant & 0 & $3(12 \%)$ \\
Ptosis & 0 & $4(16 \%)$ \\
Conjunctival dehiscence & $2(10 \%)$ & 0 \\
Severe pain & 0 & $1(4 \%)$
\end{tabular}

Table XII. Ocularist's assessment of cosmetic result

\begin{tabular}{lcc}
\hline Result & $\begin{array}{c}\text { Primary implant } \\
\text { group }(n=19)\end{array}$ & $\begin{array}{c}\text { Secondary implant } \\
\text { group }(n=25)\end{array}$ \\
\hline Good & $18(95 \%)$ & $7(28 \%)$ \\
Fair & $0(5 \%)$ & $15(60 \%)$ \\
Poor & $1(5 \%)$ & $3(12 \%)$ \\
\hline
\end{tabular}

Values are $n(\%)$

Values are $n(\%)$

Table XIII. Patients' assessment of cosmetic result

\begin{tabular}{lcc}
\hline Result & $\begin{array}{c}\text { Primary implant } \\
\text { group }(n=19)\end{array}$ & $\begin{array}{c}\text { Secondary implant } \\
\text { group }(n=25)\end{array}$ \\
\hline Good & $18(95 \%)$ & $14(56 \%)$ \\
Fair & $1(5 \%)$ & $9(36 \%)$ \\
Poor & 0 & $2(8 \%)$ \\
\hline
\end{tabular}

Values are $n(\%)$.

cosmetic result. In the case of patients who underwent additional surgical procedures, these assessments were deferred until 3-4 months after the surgery. The major factor influencing the ocularist's assessment was the degree of upper eyelid sulcus deformity. The fact that the patients gave better overall scores is undoubtedly influenced by comparison with a previously painful unsightly eye or with a previous severe post-enucleation socket syndrome (Fig. 3). Although subjective, it nevertheless gives some indication of patient satisfaction from this surgery.

\section{DISCUSSION}

The 'baseball' implant is safe, cheap, and easy to prepare and insert into the socket. Although donor sclera is our preferred material for covering the implant, Mersilene mesh is a satisfactory alternative when donor sclera is not readily available. ${ }^{17}$ Although it was originally described for use as a secondary orbital implant, ${ }^{15}$ and recommended as the first approach to a volume deficit in the anophthalmic socket, we feel from our study that it can also be recommended as a primary orbital implant for the patient undergoing an enucleation. The more recently introduced coralline hydroxyapatite implant has potential advantages over the baseball implant by offering both superior motility and additional support for the prosthesis for those patients who choose to undergo the second-stage drilling procedure. Shields et al., ${ }^{18}$ however, in a recent report of their experience with their initial 100 consecutive cases using the hydroxyapatite implant, found that 33 of their patients were satisfied with their cosmetic appearance and motility without the peg and declined further intervention. We have found that, in the majority of cases, the motility results of primary baseball implants can match those of our hydroxyapatite implants which have not undergone second-stage drilling and placement of a motility peg (Fig. 4). Our results show, however, that this does not occur to the same extent in the case of secondary baseball implants (Fig. 5). The baseball implant cannot, though, match the symmetrical fine saccadic movements provided by a successfully drilled and pegged hydroxyapatite implant.

Tyers and Collin ${ }^{1}$ concluded from their retrospective study that trauma should be a relative contraindication to primary implantation of a baseball implant as the extrusion rate is high in such cases. We implanted 2 patients primarily, whose indication for enucleation was irreparable traumatic disruption of the globe, with no problems, but chose to avoid primary implantation of a patient who had sustained severe trauma to the ocular adnexa as well as to the globe. We feel that each case should be judged individually; where there is uncertainty implantation should be deferred and undertaken secondarily, but preferably as soon as possible so that the extraocular muscles can be easily retrieved and attached directly to the implant.

From our experiences we advise caution in the case of patients who have previously undergone conjunctival peritomies for retinal detachment surgery. The peritomy has frequently been performed leaving a $2-3 \mathrm{~mm}$ frill of 

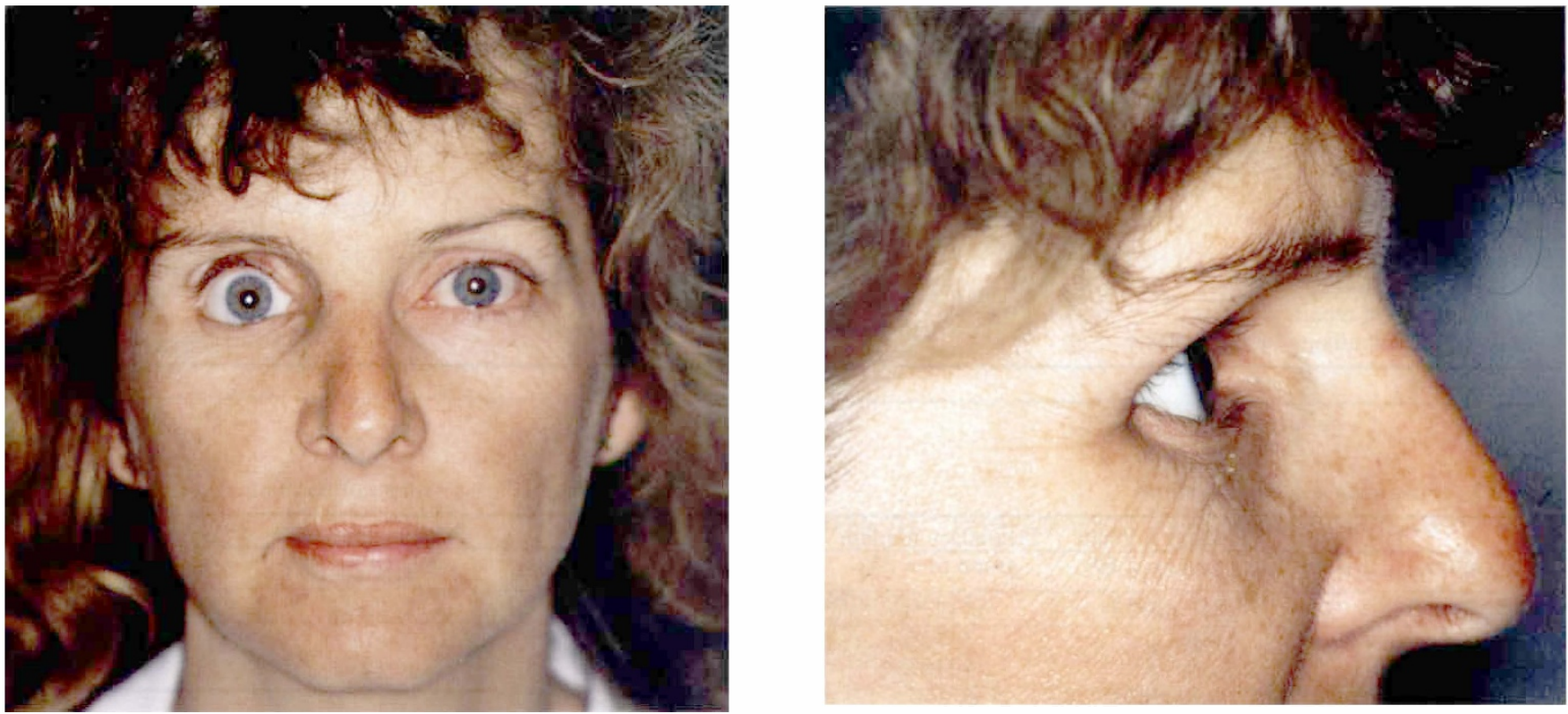

(a)
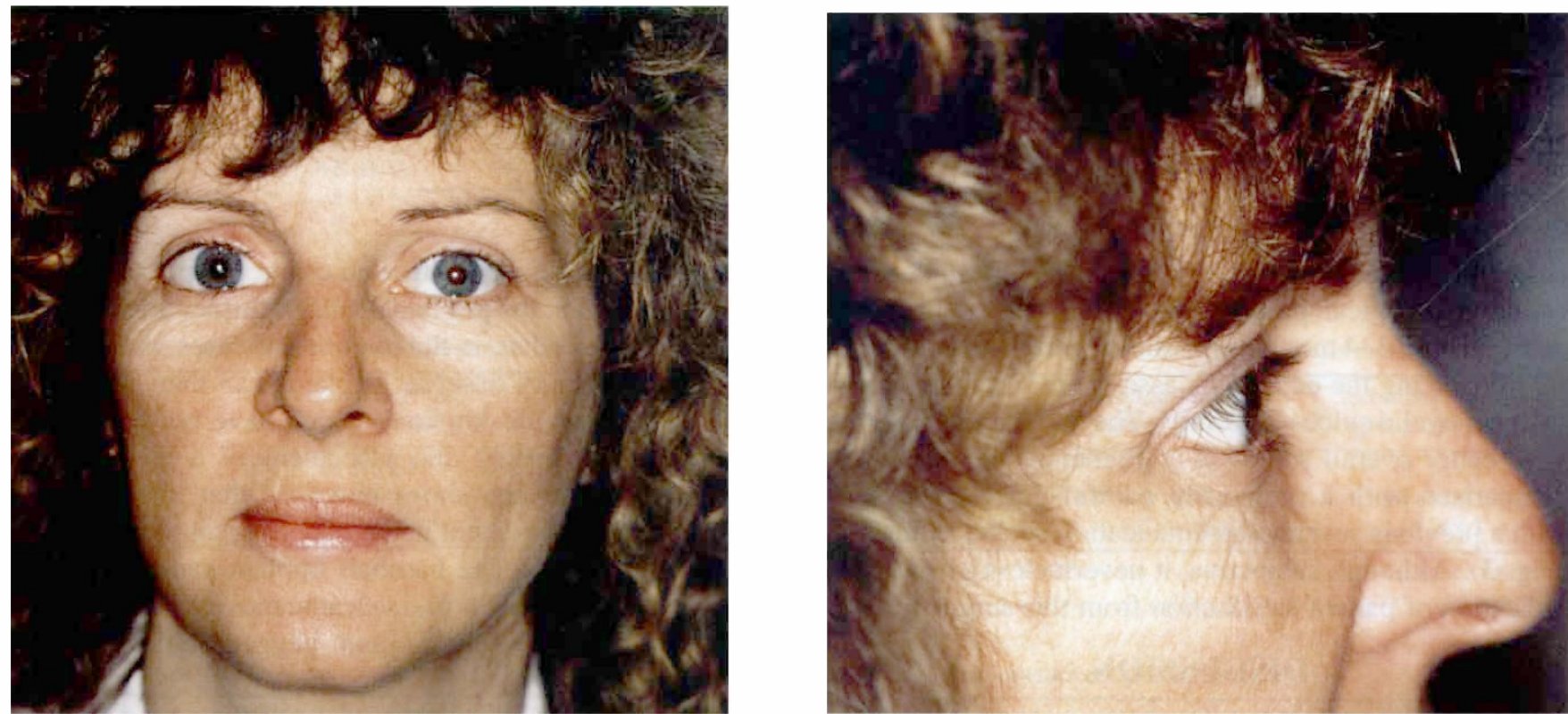

(b)

Fig. 3. (a) A patient with a post-enucleation socket syndrome demonstrating upper lid retraction, enophthalmos, an upper lid sulcus deformity, laxity of the lower lid with early entropion, and a backward tilt of the prosthesis. (b) The same patient following secondary orbital implantation with a 'baseball' implant showing successful correction of all the features of the post-enucleation socket syndrome.

conjunctiva at the limbus. This conjunctiva is adherent to the globe and cannot usually be preserved at enucleation. This can leave a conjunctival lining deficit at the time of enucleation resulting in tension at the central conjunctival suture line. Attempted direct closure of the defect also risks loss of the fornices. Two of our primary implantation patients, both of whom had previously undergone retinal detachment surgery, developed a dehiscence of the conjunctival wound requiring a simple conjunctival resuture in one case and a small buccal mucous membrane graft in the other. These patients experienced no further problems. In this situation, one should be prepared for the necessity to perform a primary mucous membrane graft.

Secondary baseball implantation should be avoided in patients with marked socket contracture. Such patients are better rehabilitated using dermis fat grafts which can address not only the volume deficit of the anophthalmic socket but also the lining deficit.

There were no extrusions in our series. We feel that this is the result of a number of factors: the use of exclusion 


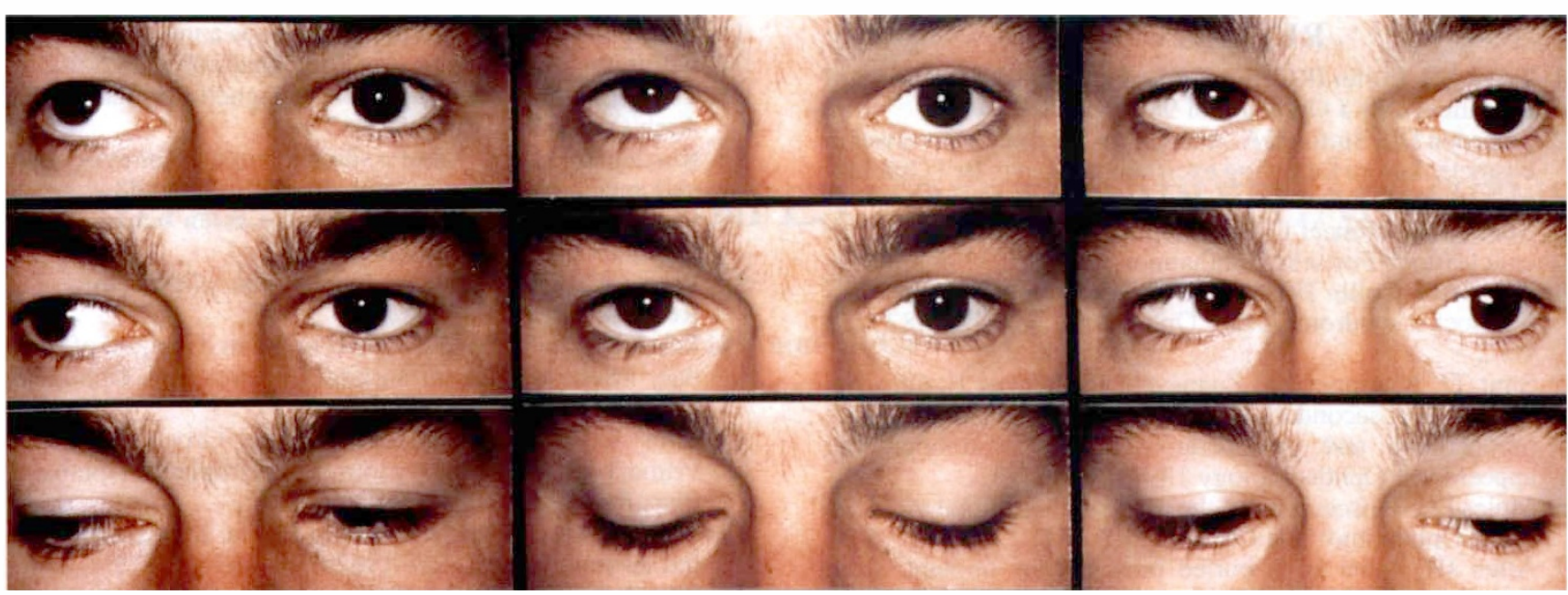

Fig. 4. A patient demonstrating good motility of the prosthesis following primary orbital implantation.

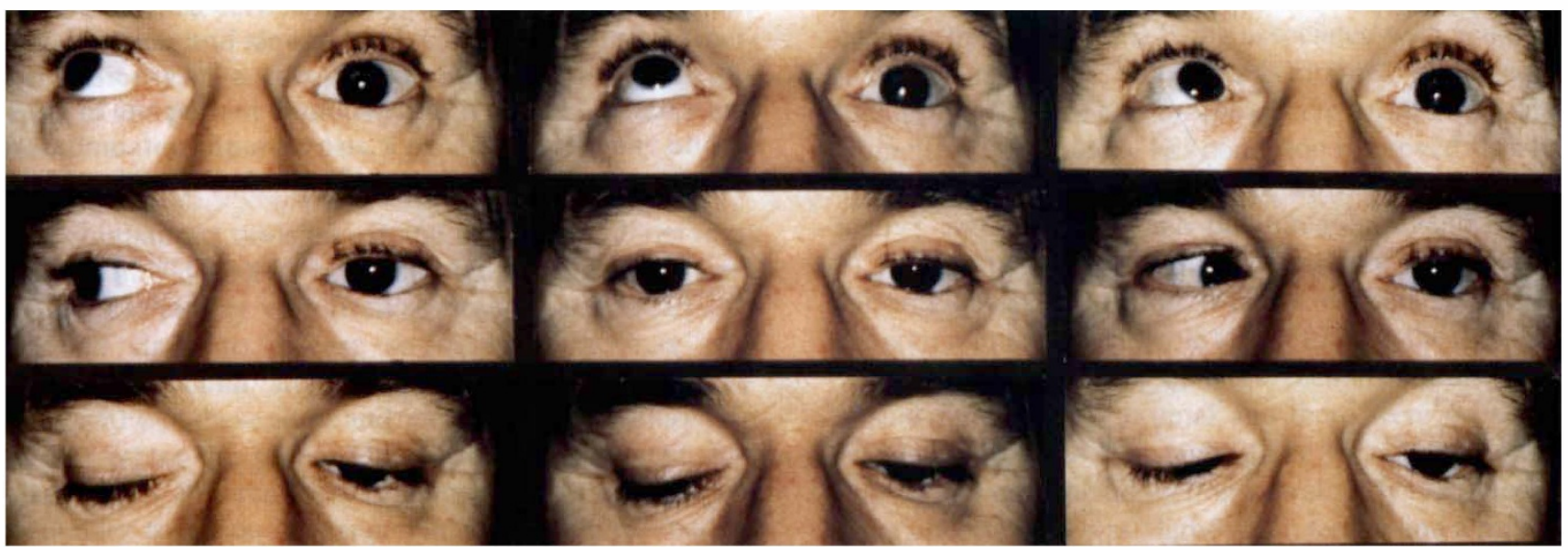

Fig. 5. A patient demonstrating poor motility of the prosthesis following secondary orbital implantation.

criteria for primary and secondary implantation, the use of precautions against excessive post-operative socket oedema (compressive dressings, non-steroidal antiinflammatory drugs), precautions taken to prevent infection (prophylactic antibiotics and a strict aseptic surgical technique), the placement of an appropriately shaped and sized post-operative conformer by a trained and experienced ocularist, and placement of the implant into the intraconal space with closure of posterior Tenon's capsule over the implant. Placement of the implant into this location was described in 1972 by Soll. ${ }^{19}$ We believe that the use of this surgical technique has contributed significantly to the absence of any extrusions in this series.

In a retrospective study published in 1990, Smit et al. ${ }^{16}$ compared the results of primary and secondary baseball orbital implants. They concluded that primary implants have distinct advantages over secondary ones because they produce fewer complications and reduce the need for additional surgery. The overall results of this prospective single surgeon study certainly support this conclusion. Anophthalmic patients who require secondary orbital implantation should be warned of the likelihood for the need for additional socket surgery.
It must be emphasised that the success of this procedure relies heavily on the skill of the ocularist. A poorly manufactured 'stock prosthesis' will certainly result in an inferior cosmetic appearance and may cause discomfort, discharge, and ultimately an increased extrusion rate from mechanical trauma to tissues overlying the implant. The availability of suitably qualified and trained ocularists working in close cooperation with the surgeon is of paramount importance.

The practice of subjecting patients to a simple enucleation without orbital implantation, a practice all too often seen in many ophthalmic units throughout the United Kingdom, should be avoided unless there is a specific contraindication to orbital implantation. It is traumatic enough to lose an eye. Such a traumatic event should not be further compounded by the disfiguring appearance of the resultant post-enucleation socket syndrome.

We wish to thank the staff of the Department of Medical Illustration, Manchester Royal Eye Hospital, for their assistance.

Key words: Anophthalmic, Baseball, Enucleation, Orbital implant, Socket. 


\section{REFERENCES}

1. Tyers AG, Collin JRO. Baseball orbital implants: a review of 39 patients. Br J Ophthalmol 985;69:438-42.

2. Smerdon DL, Sutton GA. Analysis of the factors involved in cosmetic failure following excision of the eye. Br J Ophthalmol 1988;72:768-73.

3. Smit TJ, Koornneef L. Is an implant always necessary after enucleation? Fortschr Ophthalmol 1990;87:533-6.

4. Tyers AG, Collin JRO. Orbital implants and post-enucleation socket syndrome. Trans Ophthalmol Soc UK 1982;102: 90-2.

5. Smit TJ, Koornneef L, Zonneveld FW, Groet E, Otto AJ. Primary and secondary implants in the anophthalmic orbit: preoperative and postoperative computed tomographic appearance. Ophthalmology 1991;98:106-10.

6. Mules PH. Evisceration of the globe with artificial vitreous. Trans Ophthalmol Soc UK 1885;5:200-6.

7. Allen JH, Allen L. A buried muscle cone implant. Arch Ophthalmol 1950;43:879-90.

8. Spivy BE, Allen L, Burns CA. The Iowa enucleation implant. Am J Ophthalmol 1969;67:171-8.

9. Atkins AD, Roper-Hall MJ. Magnetic orbital implants. Br J Ophthalmol 1983;67:315-6.
10. Smith B, Petrelli R. Dermis fat graft as a moveable implant within the muscle cone. Am J Ophthalmol 1978;85:62-6.

11. Tomb EH, Gearhart DF. A new magnetic orbital implant. Arch Ophthalmol 1954;52:763-8.

12. Ruedeman AD Jr. Use of a silicone implant for evisceration and enucleation. Am J Ophthalmol 1962;54:868.

13. Dutton JJ. Coralline hydroxyapatite as an ocular implant. Ophthalmology 1991;98:370-7.

14. Perry AC. Advances in enucleation. Ophthalmic Plast Reconstr Surg 1991;4:173-7.

15. Frueh BR, Felker GV. Baseball implant: a method of secondary insertion of an intraorbital implant. Arch Ophthalmol 1976;94:429-30.

16. Smit TJ, Koornneef L, Mourits M, Groet E, Otto AJ. Primary versus secondary intraorbital implants. Ophthalmic Plast Reconstr Surg 1990;6:115-8.

17. Hughes JD, Downes RN, Kemp E. The Mersilene covered intraorbital implant. Eye 1992;6:484-6.

18. Shields CL, Shields JA, De Potter P. Hydroxyapatite orbital implant after enucleation: experience with initial 100 consecutive cases. Arch Ophthalmol 1992;110:333-8.

19. Soll DB. Enucleation surgery: a new technique. Arch Ophthalmol 1972;87:196-7. 